\title{
Erratum to: On the FEM Analysis of Higher-Order Shear Deformable Beams: Validation of an Efficient Element
}

\author{
Rahmat Kazemi Firouzjaei ${ }^{1}$ - Reza Attarnejad ${ }^{1,2,3}$. \\ Rohollah Abbasi Shanbehbazari ${ }^{1}$ • Fardad Aala ${ }^{1}$
}

Published online: 27 October 2015

(C) King Fahd University of Petroleum \& Minerals 2015

\section{Erratum to: Arab J Sci Eng \\ DOI 10.1007/s13369-015-1814-7}

The original version of this article unfortunately contained a mistake. The name of the fourth author Fardad Aala was incorrectly given as Fardad Ala. The original article was corrected.

The online version of the original article can be found under doi:10.1007/s13369-015-1814-7.

Rahmat Kazemi Firouzjaei

kazemi.rf@gmail.com

1 School of Civil Engineering, College of Engineering, University of Tehran, P.O. Box 11365-4563, Tehran, Iran

2 Centre of Numerical Methods in Engineering, University of Tehran, Tehran, Iran

3 Centre of Excellence for Engineering and Management of Infrastructures, School of Civil Engineering, University of Tehran, Tehran, Iran 